\title{
SAN AGUSTÍN: DE LOS UTÓPICOS ANCESTRALES LITOLENGUAJEROS A LOS DISUTÓPICOS CO-CREADORES COLOMBIANOS SIGLO XXI
}

\author{
José Uriel Leal Zabala \\ Docente Universidad Colegio Mayor de Cundinamarca \\ uritolima@hotmail.com
}

En el primer trabajo del año 2006 sobre la práctica pedagógica realizada en el lugar ancestral de San Agustín, con los estudiantes de tercer semestre de Licenciatura y que llamé: "UNA PERCEPCIÓN DEL MUNDO MITOPOÉTICO Y PENSAMIENTO COSMOGÓNICO DE LOS ANCESTRALES LITOLENGUAJEROS DEL HUILA", invitaba, en ese entonces, tanto a los mayeutas estudiantes como a los docentes que intervinieron en esta práctica investigativa a que escribiéramos sobre la experiencia y, como resultado de estas reflexiones, nos atreviéramos a presentar soluciones a las problemáticas que aquejan a nuestra comunidad occidental, y de paso nos condujeran hacia la reconstrucción de la Identidad Colombiana.

En el presente trabajo, pretendo aportar algunas apreciaciones mías sobre la inquietud de ese entonces, pues la urgente necesidad de renovación social y transformación individual de los Colombianos lo exige y requiere.

Abordaré las temáticas, describiendo los términos utilizados en el título, para que el lector tenga cierta claridad sobre el cómo deseo se interprete mis aportes y propuestas surgidas en esta tercera incursión pedagógica a este maravilloso sitio precolombino.

Se refiere a que este pueblo, asentado hace milenios en las tierras del alto Magdalena, lograron lo "imposible"; es decir, este colectivo humano se preparó conscientemente para realizar sus propósitos más caros: acceder a la libertad. En Ellos, la utopía representó una integración ideal de una situación política, social y religiosa largamente contemplada. Sus Litos (piedras volcánicas talladas) constituyen huellas indelebles al tiempo y al espacio, que nos hablan de las costumbres e idearios de estas gentes y de su posicionamiento frente a la cotidianidad y trascendencia humana. Para ellos, su utopía no era un simple sueño genérico 0 aspiración colectiva para huir 0 evadir la realidad.

Era, y muy posiblemente fue, utilizada para transformar la realidad en acto y adquirir un cuerpo coherente y consistente de auténtica renovación espiritual y física, con el propósito de acceder a la senda del conocimiento y a las infinitas posibilidades que nos ofrece nuestro misterioso universo. Y, como desaparecieron también misteriosamente, cuando alcanzaron su máximo esplendor, es que reivindico el nombre de UTÓPICOS" para Estos seres que nos señalaron una senda, un camino, un portal a descubrir.

En los Ancestrales del alto Magdalena, su "utopía" etimológica y pragmáticamente puede concebirse como un "no-lugar", la negación del lugar presente en aras de un lugar imaginario, amarrado a la fuerza de un exilio 0 al deseo de exilio expresado en una fuerza colectiva de un formidable pueblo que venía emigrando del profundo Amazonas. Para Ellos, el propio lugar se tornó extraño y se extrañaron buscando otro espacio, con desplazamiento imagético y real. Indudablemente cultivaban un pensamiento excéntrico, pues todas sus energías se invirtieron en la adaptación a un entorno nuevo e inabordable para los "occidentales".

Tuvieron que dislocar el tiempo y el espacio. No existe utopía sin ucronía: ningún lugar, ningún tiempo. Ellos trascendieron el tiempo y disolvieron los espacios. Entrelazaron diatopía y diacronía. Todos sus lugares entraron en rivalidad con el espacio y los tiempos habituales." Murieron" para su 
época y, su escritura lítica semeja la botella de la esperanza enviada, como un sonar, al Mar de las tempestades humanas. Una preciosa botella "hipogea" que navega en nuestras mentes como herméticos mensajes fúnebres en forma de crisálidas, prontas a volar en los imaginarios de las posibilidades inauditas.

Tal vez fueron románticos nostálgicos que aspiraron actualizar un no-tiempo y un no-lugar perdidos, 0 que prefiguraron una destinación inédita para la especie humana, que sirviera de redención a los dolemas del vivir y existir terrestre. Su religiosidad utópica intenta organizar la esperanza humana y responder a la pregunta fundante de toda teología y teodicea: ¿De dónde venimos, para donde vamos y cómo podemos trascender, siendo tan intrascendentes y accidentales?

Por su extrañamiento del mundo y su alejamiento de los tiempos y de los espacios cotidianos fueron "locos-sabios" que como Moro, Bacon o Campanella, lograron encender y serenar el pensar pulsando al mismo compás las cuerdas del demens y de sapiens. Ese "desatino controlado" fue creativo y efectivo, pues lo regularon y nos lo heredaron mediante la escritura en piedra imperecedera y, por la enteogénica imaginación reflejada en las deidades zoomórficas del infra y supramundo.

En la actualidad, las cosas se complican para estos nuevos habitantes, pues estamos en la era del biopoder (según Foucault, se refiere a la organización del dominio como control de la reproducción de la vida en general), las tecnologías y su desenfrenado automatismo han socavado el ámbito prefigurador de la utopía. La utopía ha perdido su inocencia y su poder de ensoñación. "¿Cómo pensar la utopía en el mundo contemporáneo, cuando la globalización reúne todos los lugares en un lugar, anula los distintos trayectos para sincronizarlos con la hora cero del fin del tiempo, convierte la casa en mundo y hace del mundo una casa aunque bien estratificada, inquilinato inmenso abajo, mirador y pasarela de sádicos arriba?".

...0 como lo sugiere Sloterdijk (1) cuando argumenta que "la globalización es la consumación histórica del proceso de domesticación iniciado en el neolítico. Consumación, puesto que se trata de una domestica- ción global bajo el imperio del biopoder, alianza de la mathesis universalis y del triedro epistemológico que describiera Foucault, pero hoy con las características de informática, biogenética y economía como claves de la organización de los códigos sociales y culturales y de sus modos de circulación". "La sociedad global pseudoneoliberal (2) se modela en esas dos cajas negras contempo-ráneas:

Las que guardan los secretos militares (los distintos pentágonos) y los secretos sociales y personales (las pantallas "mágicas" de la televisión y del computador), tras las cuales se adivina el rostro poliforme del capital cultural, y esos "huecos negros" que son las agencias de publicidad y de marketing que regulan la producción y circulación del deseo", Tanatocracia y algo que se podría llamar con un neologismo como "Eudemonocracia (eudomonismo es la exaltación del goce y, aquí, indica a todos aquellos que organizan el parque humano de diversiones como una fiesta para el disfrute voyeurista) configuran una suerte de hidra cuyas cabezas se clonan por millones como pequeños chips narcisistas en una suerte de Matrix Universal.

Es por tanto, como toda hidra, ubicua, omnipotente, prepotente, elástica y extensa... y esta hidra con sus dos grandes cabezas (Fámulo: familia y esclavismo) no funciona si no es por medio de la reproducción a pequeña escala del hogar, donde la infantilización de la que habla Tocqueville se consagra, lo mismo que en la escuela y en la universidad donde éstas la prolongan con sus dispositivos pedagógicos: pues vale recordar que pedagogía proviene de paidoságein, conducir a los niños, algo que es contrario del todo a la psicagogia que es guiar a través de la psique y que en ello es análoga al arte mayeutico, porque en estos dos casos el imperativo es el mismo: conócete a ti mismo, muy diferente a un modelo como el de la pedagogía que atiborra de saber en proporción directa a la obturación del sujeto con sujeto de símismo ".

Hoy, más que nunca, necesitamos re-construir y actualizar el pensamiento de esos hombres y mujeres para poder configurar nuestra propia utopía que convoque dos propósitos: de un lado librar una implacable lucha por una sociedad que excluya la explotación y la opresión y, por otro lado que ofrezca las condiciones para una realización integral de sus miembros. 
Dos desafíos que, por su grado de dificultad, parecerían imposibles, y que precisamente por eso, son utópicos.

La preocupación por la restauración de un ejercicio político sano, tanto en la vida práctica como en la intelectual, es hoy en día prioridad, para plantear una solución posible. Como el sentido de la historia no está trazado por la divinidad o por el destino o por una ciencia omnisapiente, depende de nosotros mismos, de lo que podamos hacer en el aquí y en el ahora, porque nuestro accionar presente es el que moldea decisivamente el futuro. De ahí que la política, como espacio de la acción y decisión, del diálogo y de la confrontación, sea el eslabón primordial de la toma de conciencia de los seres humanos.

Nosotros, los latino- Americanos, con un histórico destino laberíntico, somos los depositarios de un dolor universal reflejado en su diversidad cósmica; somos una gran región atravesada por el espíritu de las utopías trashumantes, de los gigantescos desplazamientos, de los glocales encuentros de desencuentros entre etnias indígenas, africanas, árabes, gitanas y españolas, todos extrañados de sus tierras y de si mismos.

América Latina es unos topos que se convirtió en utopos, por sus perpetuos desplazamientos y desarraigos y, a la vez, es la tierra de la redención, de la utopía de la esperanza, donde la razón no se cierra si no que espera lo inesperado como acto mesiánico e imposible de probar.

Tenemos el poder de ir construyendo recados utópicos que señale una luz, una grieta que traspasé la domesticación global contemporánea. Unos de esos recados podría decir que todas las revoluciones han fracasado (sea religiosa, económica y político) por que no han configurado un "hombre nuevo", sino que pretende cambiar los paradigmas y los gobernantes, y acto seguido esperan que por acto de magia el hombre se redima. Otro utópico y esperanzador recado sería recabar en la condición humana para despertar una sabiduría, y uno más bello sería el de que el turno de la utopía pasa hoy por el meridiano de la educación y la cultura, pero ambos, nuevos, inspirados en la psicagogia, el arte mayéutico, la formación del sujeto, la sabiduría por encima del saber, del hacer, del sentir; pensar en trama y vinculado al saber ser y saber vivir en el contexto propio de nuestros países latinos y de pie frente al mundo.

Marx era un utópico respecto a la condición humana, cuando en la sección sobre el fetichismo de la mercancía del capítulo 1 del Capital dijo: "el reflejo religioso del mundo real solo desaparecerá cuando las condiciones de vida diaria, laboriosa y activa, representen para los hombres relaciones claras y racionales entre si y respecto a la naturaleza".

Hoy sabemos que nuestra sociedad y nuestros gobernantes no han sido claros ni transparentes y han aniquilado hasta las ilusiones más caras de la humanidad. Quizás por eso, el renacimiento de las ilusiones, lejos de ser una condición de la dominación, se presente como constitutivo y necesario de toda forma de relación social.

El siglo $x X$, en nombre de la comunidad y de los ideales colectivos ha desplegado la barbarie sin precedentes históricos que la supere, pues se volvieron guerras mundiales y exterminio atómicomasivo; también demostraron que la violencia y el conflic-to son constitutivas de la condición humana y que la propiedad privada no es el único motivo de la discordiay matanza entre la especie.

El eminente Freud (3), que alcanzó a vivir los primeros 40 años del siglo xx, en plena conflagración escribía: "la guerra en la que no queríamos creer estalló y trajo consigo una terrible decepción, no es tan solo más sangrienta y más mortífera que ninguna de las pasadas, a causa del perfeccionamiento de las armas de ataque y defensa, si no también tan cruel, tan enconada y tan sin cuartel, por lo menos, como cualquiera de ellas. Infringe todas las limitaciones a la que los pueblos se obligaron en tiempos de paz (...)derriba, con ciega cólera, cuanto le sale al paso, como si después de ella no hubiera ya futuro alguno ni paz entre los hombres. Desgarra todos los lazos de solidaridad entre los pueblos combatientes y amenaza dejar detrás de sí un encono que hará imposible, durante mucho tiempo, su reanudación. Ha hecho, además, patente el fenómeno, apenas concebible, de que los pueblos civilizados se conocen y comprenden tan poco, que puede revolverse, llenos de odio y aborrecimiento, unos 
contra otros “

Por todo lo vivido en estos históricos 11600 años de guerra y exterminio, soñar con sociedades basadas en la armonía ya no es posible; ni tampoco se puede esperar que la sociedad supere el conflicto y el enfrentamiento entre los hombres. Lo que si podemos hacer es que la "democracia" reconozca el conflicto como constitutivo de las relaciones sociales y de su insuperabilidad y que más bien construya 0 re-cree los espacios institucionales y simbólicos que faciliten el desarrollo del conflicto, de tal suerte, que su ejercicio no conduzca a la eliminación física del contrario 0 a su anulación como otredad. Se podría utilizar el conflicto como fuerza creadora, como fuente primordial de integración y cohesión social, como lo han demostrado eminentes sociólogos.

A estas alturas quiero traer algunas reflexiones del profesor Alberto Valencia Gutierrez (4), en su ensayo "Marx y la utopía de una nueva sociedad", y que nos ayudaría enormemente a configurar nuestra disutópica propuesta: "El capitalismo, con el desarrollo de las fuerzas productivas y las múltiples formas de socialización del trabajo, prepara en su propio seno las características de la nueva sociedad socialista, algo similar haría el socialismo con el comunismo. El hombre práctico, el que actúa y el que decide, debe entender en primer lugar cuáles son las tendencias reales que existen en un momento dado de la historia, para construir con base en ellas lo que considera posible y deseable, es decir, su proyecto político. Entre el ser y el deber ser no existe solución de continuidad. La lucha por el socialismo no es un ideal utópico sino una manera de estar a tono con el proceso histórico que, tiende, querámoslo 0 no, hacia esa meta. La historia tiene un sentido implícito $(\ldots) "$

El proyecto mismo de fundar una ética y la política sobre la base de la ciencia se ha demostrado equivocado frente al carácter creador de la acción humana, que encuentra nuevos rumbos a cada instante y hace impredecibles los eventos futuros... no obstante, esos mismos ideales éticos y políticos, en contra partida, han tenido una inmensa significación como causa eficiente de múltiples cambios en la sociedad contemporánea.

El hecho parece paradójico: Marx ha fracasado como promesa de realización efectiva, pero no ha fracasado en su capacidad de proponer pautas a la sociedad contemporánea. Los ideales Marxistas han triunfado, indirectamente, allí donde menos se esperaba y probablemente Marx no deseaba que lo hiciera, ya que su aspiración no era contribuir al desarrollo de la moderna sociedad burguesa sino derrumbarla" (5)

\section{LOSDISUTÓPICOS}

\section{CO-CREADORES COLOMBIANOS SIGLOXXI:}

Ante el derrumbamiento de todas las utopías que prometió y no cumplió el capitalismo, nos queda la posibilidad de repensar la sociopolítica bajo una nueva sintaxis. Se hace necesario, significativa y útil a la hora de replantear las preguntas sobre nuestra existencia actual y hacia dónde vamos. Si aceptamos la anacronía de nuestros presupuestos, tenemos que dar lugar a ese otro no-lugar que es la disutopía. Esta nos permitiría recuperar la esperanza, rumiar la palabra, sentarnos en ella, volver a extender nuestros mapas interpretativos y redefinir la política en esta posmodernidad.

La disutopía devela el enigma de todas las modernas utopías, recuperando la fuerza creativa de la subjetividad, la pasión imagética de la filosofía y el incalculable poder de la colectividad organizada como poder constituyente. El poder constituyente se refiere al poder que constituye; al DEMOS, concebido como pluripueblo que cobra fuerza creativa en la constitución por su intención constitucionalizante reflejada en su jurisprudencia y su filosofía política. "La disutopía es la forma política del poder constituyente compuesta de sus propias valencias metodologicas, histórico-filosófica y éticas"(6); ...la disutopía es la democracia: "...aquí Democracia significa expresión multilateral de la multitud, radical inmanencia de la potencia, exclusión de todo signo de definición externa, sea trascendente 0 trascendental, de todos modos externo a este radical absoluto terreno de inmanencia. Esta democracia es lo opuesto del constitucionalismo como poder constituido, impermeable a las modalidades singulares del espacio y del tiempo, como máquina predispuesta no tanto al ejercicio de la potencia cuanto al control de su dinámica de órdenes de fuerzas inmutables".

Los pueblos globalizados agotaron sus utopías y se 
sumieron en la incertidumbre, en la corrupción generalizada que fractura la posibilidad ontológica, y nos conduce a la disolución. Es un apocalipsis de frustración utópica, cuyo resplandor mortífero devasta todas las naciones, llevándolas a una encrucijada. Colombia tiene todos los síntomas de esa crisis social que deviene de la decadencia humana del capitalismo. Los ricos cada vez más ricos y los pobres cada vez más pobres. Esto nos recuerda la cena de Bush con empresarios en el documental Fahrenheit 9/11 donde habla del círculo íntimo de los que tienen y de los que tienen aún más $y$, que Robert Merton en su ensayo lo llama: "El efecto Mateo", en el cual habla de la expresión evangélica: "Porque a los que tienen, se les dará más, y a los que poco tienen, se les quitará incluso lo que tienen"(7).

Esta sociedad Demofascista del espectáculo basada en su antigua arma: EL MIEDO y que hoy la camuflan bajo la superstición del deseo de mercancía y placer de consumo) y que nos deja estupefactos e impotentes, toca fondo y se demuestra que no está blindada, que se puede derrotar, desde adentro, que es posible su derrumbe mediante el desarrollo de las potencialidades revolucionarias del DEMOS.

La paradoja de la sociedad espectacular o de la sociedad imperio que consiste en que por un lado unifica y envuelve dentro de sí a cada elemento de la sociedad, por otro lado no puede mediar efectivamente esas diferentes fuerzas sociales, crea las condiciones de un nuevo contexto, de ese nuevo medio de pluralidad y singularidad lo suficientemente fuerte, para que ese nuevo ambiente rompa dichas estructuras de poder y el poder de las estructuras y se de una revolución en todos los ámbitos. Debemos aprovechar esa deflación o resquebrajamiento de la base de la sociedad espectacular.
LA APUESTA CO-CREADORA

DE LOS COLOMBIANOS SIGLOXXI:

En este tópico rescato los elementos utópicos y programáticos planteados por Carlos Uribe Célis (8) que bien pueden trazar las bases de nuestra disutópica propuesta política con implicaciones económicas, sociales, culturales, demográficas para el futuro de Colombia. Es disutópica (utopía de utopías) en el sentido de que cuestiona, fractura y trasciende los parámetros que el actual sistema concibe como innegociable, inamovible e irrenunciables:

- La recuperación de la soberanía nacional es el estadio necesario inmediato que debe preceder a la búsqueda de la unión estratégica de los amigos y hermanos contra el enemigo común.

- La búsqueda de la solidaridad mediante la reunificación de la patria Bolivariana (ColombiaVenezuela y Ecuador) deben reunirse en un solo bloque bajo el ideal Bolivariano.

- Construir una economía con necesarias restricciones dictadas por consideraciones de valor, ético, en lo que el hombre debe ser servido y todos sus derechos respetados, incluido el derecho a la diferencia.

- El empleo digno, generado en la Nación, protegiendo su industria y producción.

- Impulsar la cultura del consumo de lo nuestro, de lo autóctono.

- La cuestión demográfica debe reconsiderarse y racionalizarse como lo hace China.

- La educación y la salud deben ser gratuitas y proveídas por el Estado o la organización solidaria.

- Las opciones sexuales y religiosas serán materia de libre elección individual.

- La igualdad debe ser un principio guía, que facilite el libre ejercicio de la personalidad.

- Preservar la naturaleza, volviendo a los alimentos naturales, a la medicina natural, al placer natural, a la armonía natural, al disfrute de la naturaleza y la defensa de ella.

- Negociar el conflicto guerrilla anti-sistema, cediendo territorio y haciendo pactos de convivencia y co-existencia. 


\section{PAIIEH Suscolombiana 18}

\section{Bibliografía}

1. Exile ... see the excellent essay by Freddy Tellez, 2003 "Sartre, Heidegger, Sloterdijk, or the controversy of humanism" in Almargen (Bogotá): 7y8, September and December, p.57-87.

2. Pseudoneoliberal say because there are four large and powerful exceptions to the theory of "free" market: first, regulation of migration flows, and second, the definition of prohibited drugs as an evil, which the more expensive as a desired commodity prices artificially inflated, third, the amount of agricultural subsidies would have to free trade and fourth, the "invisible hand" that regulates the market, that it is God, but the control bound to cyber security: Pentagon and Microsoft, for example, Falconview project design, staged in Iraq.

3. Sigmund Freud, Thoughts for the Times on War and Death, in Complete Works, Volume II, Madrid: Editorial Biblioteca Nueva, 1973 pag.2103.

4. VALENCIA ALBERTO GUTIERREZ. Marx and the utopia of a new society.Palimpsest Magazine No. 4.National University of Colombia, Bogotá 2004.Pag76-83.

5. GABRIEL RESTREPO: Dancing on the tightrope of Utopia: Palimpsest Magazine No. 4. National University of Colombia, Bogotá 2004.

6. Ethics is thus the exclusion of utopia as an affirmation of alienation, and in any case, the assumption of flat trend of the relationship between crowds and power. Antonio Negri. The constituent power: Essays on the alternatives of modernity, Madrid, Prodhufi, 1994, pag.391.

7. ROBERT K. Merton, 1973, The sociology of science. Theoretical and empirical research. Madrid, Alianza, two volumes.

8. CARLOS URIBE Selis: The pillars of a new utopia. On the other Colombia.Palimpsest Magazine No. 4.National University of Colombia, Bogotá 2004. 